\title{
User-Driven Development for UK M-Health Patient Management System
}

\author{
Mohammed Bahja \\ IRAC Group, School of Computer \\ Science and Technology \\ University of Bedfordshire \\ Mohammed.Bahja@beds.ac.uk
}

\author{
Rawad Hammad \\ Research and Learning Solutions \\ King's College London \\ Rawad.Hammad@kcl.ac.uk
}

\author{
Maysara Bahja \\ GP Department \\ Urgent London Doctors \\ Maysara.Bahja@uld.Iondon
}

\begin{abstract}
M-health applications have been gaining importance in the recent years and has been the focus of many researchers due to its advantages of effective service delivery with cost-effective mechanisms. The existing $\mathrm{m}$-health systems are reviewed in this paper and many issues are identified with them, which are mostly user-centric. Whilst there are recognised standards, such as ISO 13407, which highlight the need for user centric development, the majority of application development considers low user involvement in the development process, which either results in developing a system that does not fulfil the outlined objectives or only partially doing so. Considering this issue, an agile user centred design methodology for developing an $\mathrm{m}$-health patient management system is proposed. In addition, an online questionnaire-based survey and interviews are conducted for assessing the users' needs and expectations from this patient management $\mathrm{m}$-health system. The interview and survey results indicate that cost, ease of use, accuracy, privacy, security, effectiveness, durability, adaptability, support, learnability and enjoyability are the important factors that need to be considered in a user centric design methodology. From the study, it is concluded that the results from the survey and interviews can be useful for designing and developing user centric $m$-health systems.
\end{abstract}

\section{User-Centred Development, M-health,}

\section{INTRODUCTION}

The growth of internet and communication technologies has fostered the development of various applications for the delivery of healthcare in the UK. However, to what extent the users are considered in the development of e-health and $\mathrm{m}$ health systems is a question that remains to be investigated. Over $89 \%$ of the adults in the UK have access to internet, among which $90 \%$ are male users and $88 \%$ are female. $99 \%$ of the adults aged between 16 and 34 years are using the internet, and $78 \%$ of the adults aged between 65 and 74 years are accessing internet; closing the gap on younger age groups [1, 2]. In addition, $91 \%$ of the population in UK have access to smartphones, whilst $71 \%$ of the older population aged between 55 and 75 years use smartphones and are considered as being the fastest growing adopters of them [3]. These statistics reflect the possibility of extensive deployment of mobile technologies in healthcare for the effective management and delivery of healthcare services.

An m-health patient management system is one such application that can have a significant impact on the management and delivery of healthcare
Patient Management System, Software Engineering.

services by reducing the operational costs, increasing operational efficiency, and enhancing the patient experience $[40,41]$. Whilst the NHS has offered digital tools for managing and improving health, there has been no integrated $m$-health system for patient management developed in the UK, except for a few applications of Babylon that have only focused on the limited aspects of user centric design. In addition, unlike other some developed countries, the UK is characterised by various factors, such as diversity, increasing older population and mixed population/ immigrants from various countries across the world [4, 5]. As a result, the needs and expectations of the people might vary to a large extent in various aspects relating to a service or product. Considering the population diversity, there is a need to focus on the user centred approach in developing an m-health system that can be accessed by a diverse population.

Taking these things in to account, this paper reviews and investigates the recent studies and m-health systems, in order to assess the best way forward for a user centred approach. Secondly, an online questionnaire-based survey is conducted with a diverse population in the UK to gather the needs and 
expectations of the people regarding m-health systems. Finally, a user centred development approach is proposed for developing a patient management $m$-health system for private GPs (General Practitioners) in the UK.

\section{REVIEW OF MOBILE HEALTH SYSTEMS}

A mobile health (m-health) system pertains to the use of mobile devices for the practising of medicine and public health promotion. However, the definition of $\mathrm{m}$-health has been explained using various terminologies in accordance with the use of the different technologies, such as the internet, monitoring devices, and mobile features, such as text/SMS, and internet features such as mobile applications, online chat etc. [6]. These technologies focus on enhancing the communication between the various entities in the healthcare sector, including patients, physicians, nurses, and other health related personnel for streamlining and improving the efficiency of operational processes [7]. However, it has been acknowledged that there are no universally recognised standards or methods to evaluate $\mathrm{m}$-health, and no universally accepted definition of the phenomenon, with the term often being alternatively referred to as tele-medicine, or telehealth [8]. Whilst it is generally accepted that $\mathrm{m}$ health can benefit the community of care, there are various issues and challenges that need to be addressed, including evidence of $\mathrm{m}$-health impact, international cooperation, identification of technology and medical devices etc. [9].

m-health systems have been integrated with new technologies, being investigated for the evidence of their having an impact on the delivery of services. That is, the new technologies have been deployed for various functions in $\mathrm{m}$-health frameworks such as using cloud computing technology for m-health monitoring [10], loT (internet of things) based mhealth systems [12], artificial intelligence in health and medicine [11], and many other areas. One of the important aspects of an $\mathrm{m}$-health system is that it reduces the inequalities of access to healthcare services. There are instances where the rich and powerful gain easier access to healthcare when compared to the poor and middle class, which undermines the healthcare strategy and basic rights [13]. An m-health system, hence, can be a platform for achieving proper access to healthcare for all. There are studies that have focused on the patients perspective; however, most of them have not integrated the patients or users in the development of the system, but rather, only considered the issues associated with them. In fact, technical issues, such as platform, mobile technology, chat applications etc. have been given more priority in developing the $\mathrm{m}$-health applications, while the aspects of usability have been somewhat neglected [14].
The m-health applications must be developed in line with the user experiences through the development stages, and the users must not be forced to change their behaviour to adopt the application. Most of the studies evaluate the usability aspects after developing the m-health applications/systems, and involve users only at the stage of gathering requirements [15, 16]. A recent study [15] has found some issues relating to the connectivity and usability of the system in a RCT (randomised controlled trial) to investigate the $m$-health system for education and motivation in cardiac rehabilitation. A similar study focused on the usability of m-health application has stressed the importance of user acceptance for success of any m-health system development and implementation, also highlighting the need to include usability testing in the development process [14]. In another study [16], a systematic review of 33 related studies from 4223 studies focused on the adoption of $\mathrm{m}$-health systems has identified various issues, including perceived usefulness and ease of use, design and technical concerns, cost, time, privacy and security issues, familiarity with the technology, risk-benefit assessment, and interaction with others (colleagues, patients, and management) as restricting the extensive adoption of $m$-health systems. Another similar study has found that security and privacy of data, acceptability, reliability and cost are the major issues associated with $\mathrm{m}$ health applications [20]. The majority of the issues identified in these studies are user-centric issues, and hence, the review highlights the need for adopting a user-centric approach in the design and development of $\mathrm{m}$-health systems.

Another study [17] focuses on changing the ways of managing the patients in a healthcare system. It considers assessing the barriers to the treatment related to heart failures and proposes the CHAMPHF registry design to address the issues. The design in this study involves adopting a user centric approach, where the barriers are investigated from the users' perspective. The adoption of new technology has to be integrated with the users' needs and expectations in $\mathrm{m}$-health systems in order to achieve success. However, there may be some issues with regards to including the users in the development process using new technologies. Nevertheless, such issues can be addressed using specific approaches like an agile development process, whereby users can be trained in a smart environment. A cloud robotic platform aimed at providing services to senior citizens to improve independent living and personal health management has been developed and tested in a smart environment including patients, carers and a robot [18]. The personalisation of $\mathrm{m}$-health systems can achieve enhanced usability features and user acceptance, which not only helps in better managing the services, but also, attracts the patients to manage their health effectively through greater 
participation [19]. Hence, there is a need to shift the point of research in $\mathrm{m}$-health from developing $\mathrm{m}$ health systems focusing on technology to those focusing on usability and user acceptance of such technologies, which can only be achieved using a user centric design framework.

The antecedents that affect the adoption of mobile health technologies still remain a question to be answered. There are various issues that need to be considered during m-health system development, which include the technology, user behaviours, cultural aspects etc., in addition to the needs and objectives of healthcare. Technological artefacts from the Unified Theory of Acceptance and Use of Technology (UTAUT), along with psychological behaviour concepts, such as citizens' channel preference and product selection criteria, could help $\mathrm{m}$-health developers in designing a system that would have greater acceptance [21]. It is also necessary to design a system that reflects a country or region's cultural traits [21]. A similar study focusing on developing sustainable $\mathrm{m}$-health systems has identified significant gaps in the sustainability dimensions, including the social, economic, and environmental domains as well as the development methodology [22]. It has also been elicited that lack of awareness, lack of skilled human resource, poor logistical support and resource shortage affect the effective delivery of healthcare services, which reflects the importance of the readiness of users to adopt $\mathrm{m}$-health systems. The salience of patient centred healthcare in m-health is being recognised lately in the research domain, for it is becoming increasingly clear that failing to embrace it could well result in systems that lack focus on actual treatment process/care/services. Hence, there is a need to promote and adopt a patient/user centred approach when designing m-health systems [23]. A study focusing on identifying the interface design aspects in $\mathrm{m}$-health has recommended 20 user interface design aspects under four major themes, including privacy and security; credibility; user journey support; and the task-technology-context fit, for better adoption of $\mathrm{m}$ health systems [24]. Various recent studies have recommended and identified the importance of using a user centred approach in developing m-health applications for self-management [25], $m$-health portals for physicians and patients [26], and $m$-health interventions to reduce hospital readmissions [27].

\section{USER CENTRED DESIGN FOR A PATIENT MANAGEMENT M-HEALTH SYSTEM}

A user centred design should aim at optimising the fit of product or services with how users want, need and expect to use them, rather than forcing them to change their behaviours to accommodate the products or services [28]. The design aspect can be understood from two perspectives: 'design for users' and 'design by users' [29]. Both these perspectives are user centric, but they vary according to the degree of deploying the users during the system development process. The difference between both the approaches is explained in [29], whereby 'design by users' is an effective strategy that can be used when required to make value based judgements, usually while designing bespoke applications and 'design for users' is a more appropriate strategy for designing and developing generic products. Accordingly, there are a few questions [28] that need to be addressed before adopting the user centric design methods, which include:

- Who is the users?

- What are the approaches for engaging the users?

- What are the needs and expectations of the users (objectives)?

- What are the levels of engaging the users?

- What is the role of the users in the design process?

According to ISO 13407 standard [31], there are four essential activities that need to be considered in a user centred design project, which include: requirements gathering; requirements specification; design; and evaluation. There are various user centred methods proposed for each of the activities, with the major ones being shown in the table 1.0.

Table 1.0: Popular User Centred Design Methods

\begin{tabular}{|c|c|c|c|c|}
\hline Method & Cost & Output & $\begin{array}{c}\text { Sample } \\
\text { size }\end{array}$ & When to use \\
\hline Focus group & Low & $\begin{array}{c}\text { Non- } \\
\text { statistical }\end{array}$ & Low & $\begin{array}{c}\text { Requirement } \\
\text { gathering }\end{array}$ \\
\hline $\begin{array}{c}\text { Usability } \\
\text { testing }\end{array}$ & High & $\begin{array}{c}\text { Statistical } \\
\text { and non- } \\
\text { statistical }\end{array}$ & Low & $\begin{array}{c}\text { Design \& } \\
\text { evaluation }\end{array}$ \\
\hline $\begin{array}{c}\text { Participatory } \\
\text { design }\end{array}$ & Low & Statistical & Low & Design \\
\hline $\begin{array}{c}\text { Questionna- } \\
\text { ires }\end{array}$ & Low & Statistical & High & $\begin{array}{c}\text { Requirement } \\
\text { gathering \& } \\
\text { evaluation }\end{array}$ \\
\hline $\begin{array}{c}\text { Interviews } \\
\text { High }\end{array}$ & $\begin{array}{c}\text { Non- } \\
\text { statistical }\end{array}$ & Low & $\begin{array}{c}\text { Requirement } \\
\text { gathering \& } \\
\text { evaluation }\end{array}$ \\
\hline
\end{tabular}

\subsection{Focus Groups}

The focus group method involves the use of intended or actual users of a system to share their thoughts, ideas, needs, and expectations on a certain aspect of a system or the system as a whole [31]. The individual's ideas can be discussed with those of others in the group in order to achieve 
a common set of objectives that can help in a wider adoption of the system [32]. It is commonly used for gathering requirements with a low sample population, being considered as an effective means of input to the system design.

\subsection{Usability Testing}

The usability requirements are outlined before the testing in order to analyse the effectiveness, efficiency and satisfaction for the users; tasks identified in use analysis and in scenarios [30]. Whilst the approach usually involves two actors, namely, users and developers, there might also be another person to record the issues identified during the interaction or while working on different scenarios. The users can also be assessed in terms of the time required for completing each task given to them, which can help in designing the system. This approach can be used for both designing and evaluating a system, as it helps in finding the most likely usability problems [33]. There are three aspects identified for evaluating the usability aspects, which include effectiveness and efficiency; satisfaction; and reporting usability. The MUSiC Performance Measurement Method [35] can be used for measuring effectiveness, the SUMI questionnaire for usability, and the National Institute of Standards and Technology's Common Industry Format usability tests can be utilised for reporting [30].

\subsection{Participatory Design}

Participatory design/co-design involves the users actively in gathering ideas and opinions and also engaging in the process of design and decision making [29]. This approach is used mostly in generating prototype models, which are later modified and included in the actual system design. However, this approach needs an experienced moderator who has thorough knowledge of the domain, to guide the users and who can modify the verbal requirements into system requirements and design [36].

\subsection{Questionnaires}

Questionnaires are one of the effective means of collecting information (requirements \& opinions) from a large sample population in form of statistical data, which can then be analysed [33]. Questionnaires are commonly deployed in gathering requirements and evaluation (SUMI Questionnaire) tasks in instances where the developers can only gain remote access to the users and require a larger sample population. Responses gathered through questionnaires can be statistically analysed, which increases the scientific credibility and thus, can be used as an effective method in user centred design [34].

\subsection{Interviews}

An interview usually involves one to one interaction between the interviewer and interviewee and can take various forms, such as structured (fixed set of questions), semi-structured (fixed and open ended questions), and unstructured (open ended question) [29]. The advantage of interviewing is that more qualitative information can be gathered with a lower sample population, and any misunderstandings can be quickly addressed. However, the responses from an interview are non-statistical and require handling by experienced practitioners [33].

\section{AN AGILE USER CENTRED DESIGN METHODOLOGY FOR A PATIENT MANAGEMENT M-HEALTH SYSTEM}

It was identified that, despite the international standards specifying the active involvement of users (patients \& physicians) in developing patient centred health applications, there are not many research works that have identified with such practices [37]. The importance of user centric design is stressed in many studies [30, 36, 37], and considering the rapid changes in technology as well as users' needs and expectation, there is a need to identify a model that is user centric, whilst also being able to accommodate these changes during the design and development stages. To this end, studies have been conducted on integrating the agile development process and user centred design methods [38, 39]. Considering these factors, in this study, an integrated user centric agile development methodology for developing $\mathrm{m}$-health system is proposed, which can accommodate mitigate the risks of changing needs and requirements; and also that can achieve high user satisfaction and adoption rates. The proposed methodology is presented in the figure 1 , whilst the various stages of development and the methods used are explained in the following sections.

- Identify Needs: The users of the m-health system mainly include patients, physicians, and administrators. All the three types of users are involved in the development of the m-health system using a participatory approach. Initially, the high level needs and expectations are gathered from the users using two methods. A questionnaire based survey, which will help in identifying the needs and expectations of the patients using a large sample population. The needs and expectations of the physicians and administrators can be collected using interviews, which usually require a small sample population.

- Specify Context of Use: This stage involves the identification of people who uses the system; location for deploying the system; for what it will be used; and under what conditions. Accordingly, 
the requirements are gathered. A focus group of patients, physician, and administrators is used in identifying the needs, attitudes, expectations and to collect the requirements.

- Specify the requirements: At this stage, the various types of information gathered through verbal interaction and surveys are assessed and converted into system requirements that can be integrated in to the system design by the developers.

- Design the Components/System: The components of the system are then designed individually until all of them are evaluated and are integrated with each component satisfies.

- Evaluate the Designs: Each component of the system is evaluated by involving the focus groups. If the component is satisfactory, it is integrated with the others that are deemed appropriate for developing the complete system design. An SUMI questionnaire is used for evaluating the usability of the system once it is developed fully. If an evaluated component is not satisfactory according to the users, the process is repeated until the component design is accepted for the system.

In sum, this methodology actively involves the users in the various stages of development and thus, enhances the user centric design approach. It also includes an agile strategy to accommodate the changing needs and requirements.

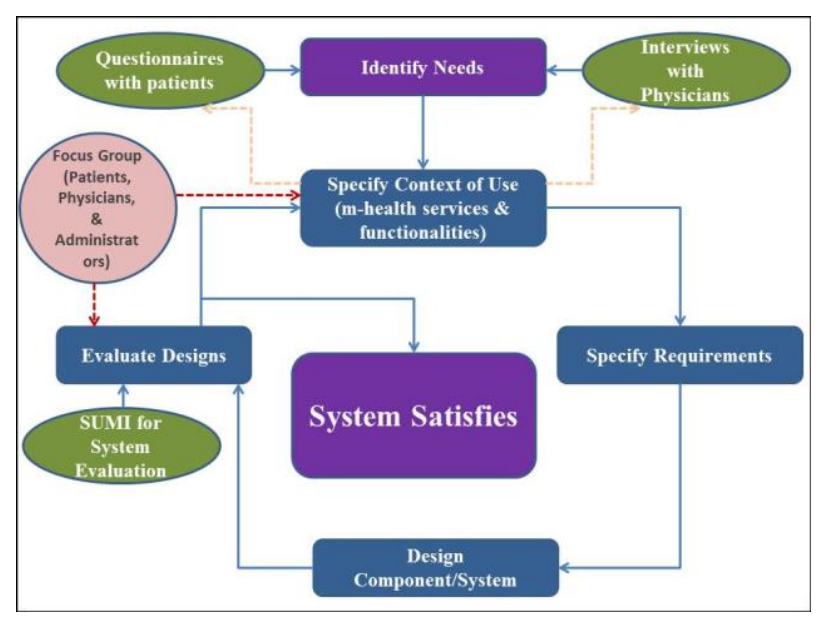

Figure 1: Agile User Centric Methodology for Developing an m-health System

\section{DATA COLLECTION}

The data collection includes two phases: first, analysing the patients' needs and expectations through data collection from an online survey questionnaire; and second, the analysis of physicians' needs and expectations using interviews. As abovementioned, questionnaires are considered to be a cost-effective, quick and efficient way of obtaining information from a large sample population [44]. Information using questionnaires can be collected quickly when the target population is diverse and large, where interviews would be impractical [45]. They can be used for measuring preferences and opinions, and can include both open ended and closed questions [45]. The sample obtained from the surveys would mainly include quantitative data (e.g. number of yes/no), which would be used for statistical analysis and is taken to represent the population, provided the analysed sample is sufficiently large [46]. Using techniques like email surveys can further boost the sample population in a limited time frame and could achieve efficient information [48]. In addition to online survey questions, qualitative information can be gathered through interviews, which are one of the powerful tools for gathering such rich information [47].

\section{1. $\mathrm{m}$-health patient online survey}

An online survey was developed for gathering the information related to the basic user needs and expectations for developing a user centric m-health patient management system. The survey design process is explained in the following subsections.

Study Setting \& Participants: The online survey questionnaire was targeted at people in the UK, being used as survey participants to gather their needs and expectations in relation to developing a user centric m-health patient management system. Accordingly, the survey was designed using Google forms, and the generated survey link was forwarded to people in the UK, mostly the researcher's colleagues, through email. The survey link was open from February, 27th 2018 to April 5th 2018, for a period of 37 days. The study was mainly conducted in UK, as the study was focusing on developing the $\mathrm{m}$-health patient management system in UK.

Questionnaire Design: The questionnaire has been designed by taking inputs relating to user centric design from the ISO/IEC 9126-1 standards, ISO 13407 Standard [31]; user centred features outlined by Witteman et al. [37], and Herscovici et al. [40]. It is divided in to two parts: the first, includes five questions focused on collecting demographic information; and the second, includes 18 multiple choice questions for gathering information on user needs and expectations from an $\mathrm{m}$-health patient management system.

Sampling: Due to the limited time available, the snowball sampling technique was used in the study to increase the sample size [47]. That is, a note was placed in the email with a survey link, which was forwarded, requesting the receivers to pass it on to their friends and colleagues. In sum, it was deemed that this process would achieve a higher sample level within the short time available. The survey link was forwarded to 404 people and the response rate achieved was 310 . 


\subsubsection{Survey Results}

The survey results are analysed using the PASW Statistics 18 tool, with which the information is exported to the tool using the excel file downloaded from the Google Forms. The results of the survey are presented in the following subsections.

\section{Demographic Information:}

The survey included 310participants i.e. $67.7 \%$ males, $29 \%$ females and $3.3 \%$ preferred not to say and most of them were distributed among the age groups $18-30$ years $48.4 \%$ and $31-55$ years $38.7 \%$, as shown in the figure 2 .

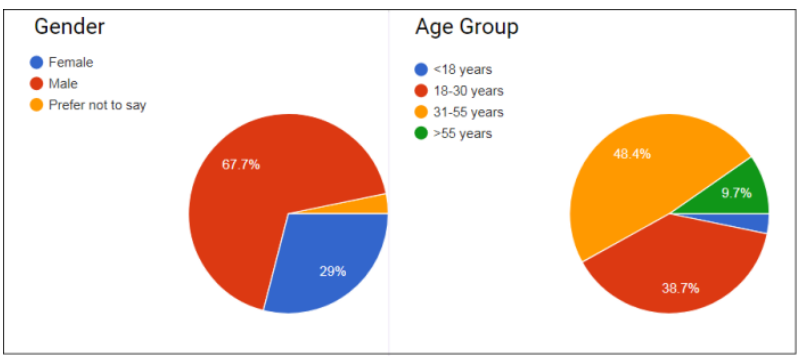

Figure 2: Gender and Age Group Distribution

The respondents were spread across the ages evenly, i.e. participants of all ages were well represented, thereby improving the overall credibility of the responses. In addition, the majority of the participants were well-educated, with $61.3 \%$ being post-graduates, $19.4 \%$ under-graduates, and $19.4 \%$ had doctorates (PhDs), as shown in figure 3. As the majority of the participants were highly educated, more effective and constructive responses could be achieved.

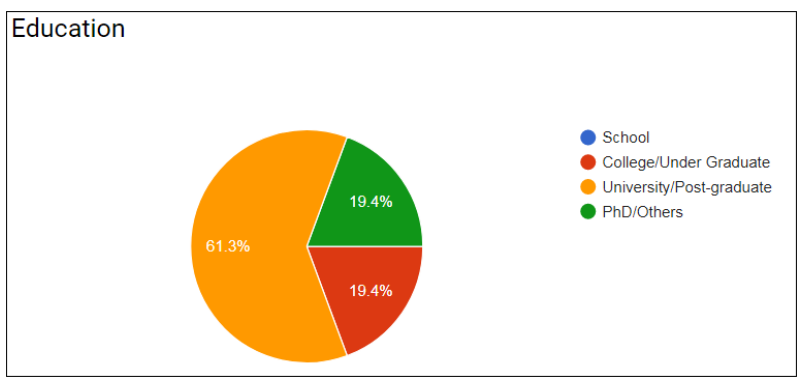

Figure 3: Education Details of the Survey Participants

The majority of the participants were using one or more devices that could be used for accessing $\mathrm{m}$ health services and the distribution of these among the participants is shown in figure 4.

Also, the majority of the participants were the users of an iPhone (iOS), and other smartphones, such as Samsung (Android). That is, the responses revealed that Apple iOS and Android were the most used mobile platforms by the participants, and that there were few who were using windows or other operating systems on their phones. This highlights the need to develop an m-health system that has the capability to work on various mobile platforms.

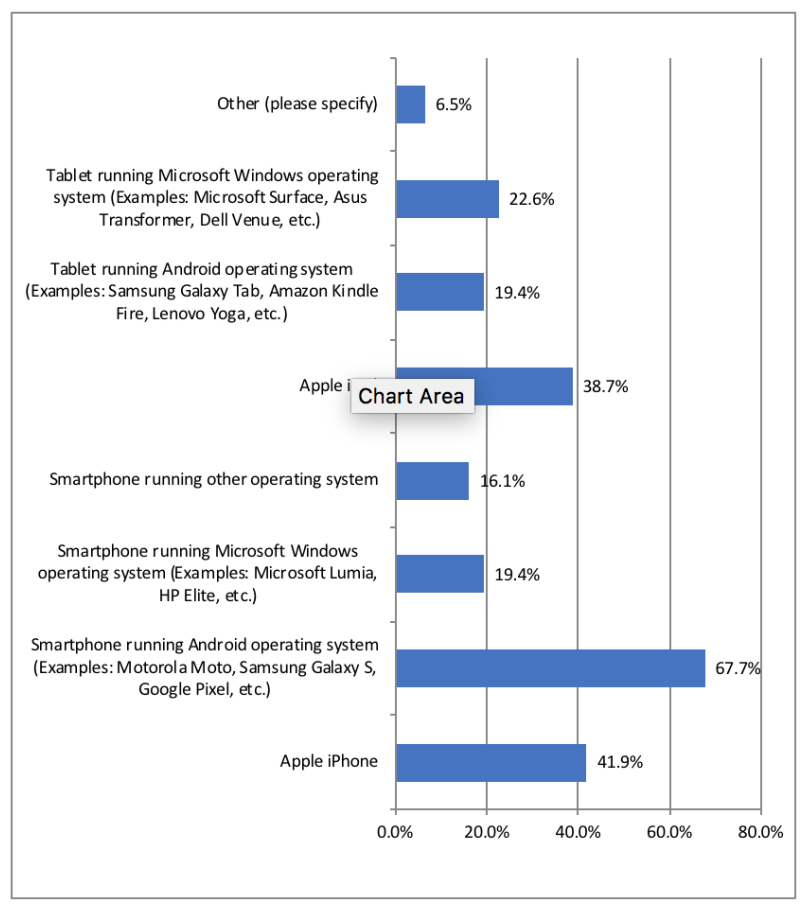

Figure 4: Devices used by the Survey Participants

Table 2: Users' needs \& Expectations from an m-health

\begin{tabular}{|l|c|c|c|c|c|}
\hline \multicolumn{1}{|c|}{ Rate } & $\begin{array}{c}\text { Not } \\
\text { Import } \\
\text { ant at } \\
\text { all }\end{array}$ & $\begin{array}{c}\text { Not } \\
\text { very } \\
\text { import } \\
\text { ant }\end{array}$ & $\begin{array}{c}\text { Neut } \\
\text { ral }\end{array}$ & $\begin{array}{c}\text { Somew } \\
\text { hat } \\
\text { Importa } \\
\text { nt }\end{array}$ & $\begin{array}{c}\text { Very } \\
\text { Import } \\
\text { ant }\end{array}$ \\
\hline Cost & 10 & 40 & 60 & 110 & 90 \\
\hline $\begin{array}{l}\text { Easy to } \\
\text { set-up / } \\
\text { installatio } \\
\text { n }\end{array}$ & 0 & 10 & 30 & 100 & 170 \\
\hline $\begin{array}{l}\text { Easy to } \\
\text { use }\end{array}$ & 0 & 5 & 15 & 90 & 170 \\
\hline $\begin{array}{l}\text { Ensuring } \\
\text { connectio } \\
\text { n with the } \\
\text { network }\end{array}$ & 0 & 14 & 76 & 90 & 130 \\
\hline $\begin{array}{l}\text { Easy to } \\
\text { integrate } \\
\text { with my } \\
\text { other } \\
\text { devices } \\
\text { and } \\
\text { technolog } \\
\text { y }\end{array}$ & 0 & 2 & 14 & 132 & 162 \\
\hline $\begin{array}{l}\text { Accuracy } \\
\text { of the } \\
\text { data } \\
\text { collected } \\
\text { if } \\
\text { applicabl } \\
\text { e) }\end{array}$ & 0 & 2 & 20 & 77 & 211 \\
\hline $\begin{array}{l}\text { Overall } \\
\text { effectiven } \\
\text { ess of the } \\
\text { app to } \\
\text { address } \\
\text { your } \\
\text { needs }\end{array}$ & 0 & 2 & 62 & 91 & 155 \\
\hline & & & & & \\
\hline & & & & & \\
\hline & & & & & \\
\hline
\end{tabular}




\begin{tabular}{|l|l|l|l|l|l|}
\hline Durability & 0 & 22 & 68 & 98 & 121 \\
\hline $\begin{array}{l}\text { Privacy } \\
\text { of my } \\
\text { data }\end{array}$ & 0 & 2 & 20 & 77 & 211 \\
\hline $\begin{array}{l}\text { Privacy } \\
\text { of my } \\
\text { activities } \\
\text { at home } \\
\text { and in } \\
\text { the } \\
\text { communit } \\
\text { y (not } \\
\text { being } \\
\text { physically } \\
\text { tracked } \\
\text { by } \\
\text { unauthori } \\
\text { sed } \\
\text { individual } \\
\text { s or } \\
\text { oftware } \\
\text { programs } \\
\text { ) }\end{array}$ & 0 & 0 & 5 & 75 & 230 \\
\hline $\begin{array}{l}\text { Sharing } \\
\text { of my } \\
\text { data with } \\
\text { others }\end{array}$ & 43 & 33 & 49 & 54 & 131 \\
\hline $\begin{array}{l}\text { Customer } \\
\text { support } \\
\text { from the } \\
\text { company } \\
\text { supplying } \\
\text { the } \\
\text { technolog } \\
\text { y }\end{array}$ & 0 & 27 & 40 & 162 & 80 \\
\hline $\begin{array}{l}\text { Enjoyabl } \\
\text { e to use }\end{array}$ & 0 & 20 & 80 & 110 & 90 \\
\hline Training & 53 & 34 & 80 & 74 & 69 \\
\hline
\end{tabular}

All the aspects regarding cost, ease of use, accuracy, privacy, effectiveness, durability, adaptability, support, and enjoyability presented in the table were considered to be important by the participants. However, the training aspect received mixed responses, with majority being neutral about this. This may be due to the fact that most were highly educated and using one or more smartphones, and may be experienced in using mobile applications and other systems over the devices.

\subsection{Interview Summary}

The qualitative data collection through interviews with five physicians (from London) provides insights into user (physicians) needs and expectations. An unstructured interview with open ended questions helped in the collection of the qualitative information, whereby this had the advantage of gathering more efficient and quality information from a limited sample population [47]. The major points observed from the interviews with respect to the physicians needs and expectations of $m$-health patient management systems are as follows.
- Privacy and information security are considered to be important concerns, as raised by all the interviewees.

- The provision for automatic monitoring was preferred by majority of them. As it is not possible for the physicians to monitor the patients' data frequently, an intelligent system was preferred to monitor them and to alert the physicians in case of any emergency.

- The majority of them preferred equal access to the system, whereby the basic diagnosis/monitoring/feedback would be assessed by staff nurses, who could alert the physicians in case of emergency.

- Easy to use, integrated views of patient data for quick review/observation, independent messaging is one of the features mentioned and appeared to be preferred by many of the interviewees.

- Learnability was another aspect mentioned, whereby the physicians need to have real time access to the learning resources for references with respect to a particular case. An integrated portal for specialist consultation was also preferred.

- Accuracy is another important aspect identified, in that the efficiency of the systems to provide accurate data without any errors was highlighted as being salient.

\section{CONCLUSION}

The scope for $\mathrm{m}$-health applications in healthcare has been increasing in the recent years with rapid developments across the technology and communication systems. There have been various $m$-health systems reviewed in this study and the majority of the issues identified have been user centric, primarily to do with privacy, security, usability, and functionalities. It has been explained that the ISO 13407 standard specifies various methods that can be used in the process of developing a user-centric m-health system. Regarding the specified methods, an agile user centred design methodology was proposed for a patient management $\mathrm{m}$-health system. In addition, a survey conducted for assessing users' needs and expectations of such a system revealed that cost, ease of use, accuracy, privacy, effectiveness, durability, adaptability, support, and enjoyability are the most important factors to be considered in its development. The interviews also highlighted other aspects, including security, learnability and usability of the system. These inputs will be used in future work focused on the development of a patient management $\mathrm{m}$-health system in the UK. 


\section{REFERENCES}

[1] Office for National Statistics, "Statistical BulletinInternet users in the UK", Ons.gov.uk, 2017. [Online]. Available: https://www.ons.gov.uk/businessindustryandtrade/it andinternetindustry/bulletins/internetusers/2017. [Accessed: 21- Feb- 2018].

[2] Clarke CS, Round J, Morris S, et al Exploring the relationship between frequent internet use and health and social care resource use in a community-based cohort of older adults: an observational study in primary care BMJ Open 2017;7:e015839. doi: 10.1136/bmjopen-2017015839.

[3] Deloitte, "UK public are 'glued to smartphones' as device adoption reaches new heights", 2017.

[4] Office for National Statistics, "Overview of the UK population: July 2017", Ons.gov.uk, 2017. [Online]. Available: https://www.ons.gov.uk/peoplepopulationandcomm unity/populationandmigration/populationestimates/a rticles/overviewoftheukpopulation/july2017.

[Accessed: 21- Feb- 2018].

[5] "The World Factbook - Central Intelligence Agency", Cia.gov, 2018. [Online]. Available: https://www.cia.gov/library/publications/the-worldfactbook/geos/uk.html. [Accessed: 21- Feb- 2018].

[6] S. Adibi, Mobile Health, 1st ed. Springer, 2015.

[7] K. Wagner, "How Mobile Health Is Changing Care Delivery | HFMA", Hfma.org, 2014. [Online]. Available:

http://www.hfma.org/leadership/mobilehealth/.

[Accessed: 21- Feb- 2018].

[8] D. Malvey and D. Slovensky, MHealth. Boston, MA: Springer US, 2014, pp. 163-165.

[9] Y. Park, "Emerging New Era of Mobile Health Technologies", Healthcare Informatics Research, vol. 22, no. 4, p. 253, 2016.

[10] B. Xu, L. Xu, H. Cai, L. Jiang, Y. Luo and Y. $\mathrm{Gu}$, "The design of an $\mathrm{m}$-Health monitoring system based on a cloud computing platform", Enterprise Information Systems, vol. 11, no. 1, pp. 17-36, 2015.

[11] Siuly, S., Huang, R. \& Daneshmand, M. Health Inf Sci Syst (2018) 6: 2. https://doi.org/10.1007/s13755-017-0040-y

[12] S. Deshkar, R.A. Thanseeh, and V.G. Menon. "A Review on loT based m-Health Systems for Diabetes". International Journal of Computer Science and Telecommunications, Volume 8, Issue 1, January 2017.

[13] I. Garcia-Subirats, I. Vargas, A. MogollónPérez, P. De Paepe, M. da Silva, J. Unger, C. Borrell and M. Vázquez, "Inequities in access to health care in different health systems: a study in municipalities of central Colombia and northeastern Brazil", International Journal for Equity in Health, vol. 13, no. 1, p. 10, 2014.

[14] O. Vélez, P. Okyere, A. Kanter and S. Bakken, "A Usability Study of a Mobile Health Application for Rural Ghanaian Midwives", Journal of Midwifery \& Women's Health, vol. 59, no. 2, pp. 184-191, 2014.

[15] D. Salvi, M. Ottaviano, S. Muuraiskangas, A. Martínez-Romero, C. Vera-Muñoz, A. Triantafyllidis, M. Cabrera Umpiérrez, M. Arredondo Waldmeyer, E. Skobel, C. Knackstedt, H. Liedes, A. Honka, J. Luprano, J. Cleland, W. Stut and C. Deighan, "An m-Health system for education and motivation in cardiac rehabilitation: the experience of HeartCycle guided exercise", Journal of Telemedicine and Telecare, pp. 1357633X1769750, 2017.

[16] M. Gagnon, P. Ngangue, J. Payne-Gagnon and M. Desmartis, "m-Health adoption by healthcare professionals: a systematic review", Journal of the American Medical Informatics Association, vol. 23, no. 1, pp. 212-220, 2015.

[17] A. DeVore, L. Thomas, N. Albert, J. Butler, A. Hernandez, J. Patterson, J. Spertus, F. Williams, S. Turner, W. Chan, C. Duffy, K. McCague, X. Mi and G. Fonarow, "Change the management of patients with heart failure: Rationale and design of the CHAMP-HF registry", American Heart Journal, vol. 189, pp. 177-183, 2017.

[18] M. Bonaccorsi, L. Fiorini, F. Cavallo, R. Esposito and P. Dario, "Design of Cloud Robotic Services for Senior Citizens to Improve Independent Living and Personal Health Management", Biosystems \& Biorobotics, pp. 465475, 2015.

[19] P. Devos, A. Min Jou, G. De Waele and M. Petrovic, "Design for personalized mobile health applications for enhanced older people participation", European Geriatric Medicine, vol. 6, no. 6, pp. 593-597, 2015.

[20] M. Baig, H. GholamHosseini and M. Connolly, "Mobile healthcare applications: system design review, critical issues and challenges", Australasian Physical \& Engineering Sciences in Medicine, vol. 38, no. 1, pp. 23-38, 2014.

[21] Y. Dwivedi, M. Shareef, A. Simintiras, B. Lal and V. Weerakkody, "A generalised adoption model for services: A cross-country comparison of mobile health (m-health)", Government Information Quarterly, vol. 33, no. 1, pp. 174-187, 2016.

[22] M. Chowdhury and M. Quaddus, "A multiphased QFD based optimization approach to sustainable service design", International Journal of 
Production Economics, vol. 171, pp. 165-178, 2016.

[23] A. Grube, T. Dehling, K. Klein and A. Sunyaev, "Promoting Use of Patient-Centered Health IT: Assessment and Ranking of Incentive Mechanisms", Hdl.handle.net, 2018. [Online]. Available: http://hdl.handle.net/10125/50293. [Accessed: 21- Feb- 2018].

[24] V. Gkatzidou, K. Hone, L. Sutcliffe, J. Gibbs, S. Sadiq, A. Szczepura, P. Sonnenberg and C. Estcourt, "User interface design for mobile-based sexual health interventions for young people: Design recommendations from a qualitative study on an online Chlamydia clinical care pathway", BMC Medical Informatics and Decision Making, vol. 15, no. 1, 2015.

[25] R. Bendixen, A. Fairman, M. Karavolis, C. Sullivan and B. Parmanto, "A User-Centered Approach: Understanding Client and Caregiver Needs and Preferences in the Development of mHealth Apps for Self-Management", JMIR mHealth and uHealth, vol. 5, no. 9, p. e141, 2017.

[26] J. Alpert, A. Krist, R. Aycock and G. Kreps, "Designing User-Centric Patient Portals: Clinician and Patients' Uses and Gratifications", Telemedicine and e-Health, vol. 23, no. 3, pp. 248253, 2017.

[27] A. Alluhaidan, E. Lee, N. Alnosayan, S. Chatterjee, L. Houston-Feenstra, W. Dysinger and M. Kagoda, "Designing Patient-Centered mHealth Technology Intervention to Reduce Hospital Readmission for Heart-Failure Patients", 2015 48th Hawaii International Conference on System Sciences, 2015.

[28] M. I. Chun, C. Harty, and L. Schweber. "Comparative study of user-centred design approaches". Procs 31st Annual ARCOM Conference, 7-9 September 2015, Lincoln, UK, Association of Researchers in Construction Management, 1125-1134.2015.

[29] K. EASON, "User-centred design: for users or by users?", Ergonomics, vol. 38, no. 8, pp. 16671673, 1995.

[30] N. Bevan, "ISO and Industry Standards for User Centred Design", Serco Ltd., 2000.

[31] R. Richey and J. Klein, "Design and Development Research", Handbook of Research on Educational Communications and Technology, pp. 141-150, 2013.

[32] R. Krueger and M. Casey, Focus groups. SAGE, 2014.

[33] C. Teoh, "User-centred design (UCD) - 6 methods", Webcredible.com, 2006. [Online]. Available: https://www.webcredible.com/blog/user- centered-design-ucd-6-methods/. [Accessed: 22Feb- 2018].

[34] Serco, Performance Measurement Handbook: Serco Usability Services - Training courses and technical enquiries, 3rd ed. London: Serco Ltd., 1995, pp. 80-170.

[35] M. Macleod, R. Bowden, N. Bevan. "The MUSiC Performance Measurement Method". National Physical Laboratory. [online] Available at: http://www.usabilitynet.org/papers/muspmm97.pdf [Accessed: 22- Feb- 2018].

[36] J. Saad-Sulonen, E. Eriksson, K. Halskov, H. Karasti and J. Vines, "Unfolding participation over time in the design of IT", CoDesign, vol. 14, no. 1, pp. 1-3, 2018.

[37] H. Witteman, S. Dansokho, H. Colquhoun, A. Coulter, M. Dugas, A. Fagerlin, A. Giguere, S. Glouberman, L. Haslett, A. Hoffman, N. Ivers, F. Légaré, J. Légaré, C. Levin, K. Lopez, V. Montori, T. Provencher, J. Renaud, K. Sparling, D. Stacey, G. Vaisson, R. Volk and W. Witteman, "Usercentered design and the development of patient decision aids: protocol for a systematic review", Systematic Reviews, vol. 4, no. 1, 2015.

[38] D. Salah, R. Paige and P. Cairns, "A systematic literature review for agile development processes and user centred design integration", Proceedings of the 18th International Conference on Evaluation and Assessment in Software Engineering - EASE '14, 2014.

[39] S. Chamberlain, H. Sharp and N. Maiden, "Towards a Framework for Integrating Agile Development and User-Centred Design", Extreme Programming and Agile Processes in Software Engineering, pp. 143-153, 2006.

[40] N. Herscovici, C. Christodoulou, E. Kyriacou, M. Pattichis, C. Pattichis, A. Panayides and A. Pitsillides, "m-Health e-Emergency Systems: Current Status and Future Directions - [Wireless corner]", IEEE Antennas and Propagation Magazine, vol. 49, no. 1, pp. 216-231, 2007.

[41] E. Kyriacou, C. Pattichis and M. Pattichis, "An overview of recent health care support systems for eEmergency and mHealth applications", 2009 Annual International Conference of the IEEE Engineering in Medicine and Biology Society, 2009

[42] NHS UK, "Home Page | Digital Apps Library", Apps.beta.nhs.uk, 2018. [Online]. Available: https://apps.beta.nhs.uk/. [Accessed: 23- Feb2018].

[43] Babylon, "| Babylon Health", Babylon Health, $2018 . \quad$ [Online]. Available: https://www.babylonhealth.com/download-app.

[Accessed: 23- Feb- 2018]. 
[44] Jack B, Clarke AM. The purpose and use of questionnaires in research. Prof Nurse. 1998 Dec;14(3) 176-179. PMID: 10095687.

[45] S. McLeod, "Questionnaire | Simply Psychology", Simplypsychology.org, 2018. [Online]. Available:

https://www.simplypsychology.org/questionnaires.h tml. [Accessed: 05- Mar- 2018].

[46] K. Popper, The Logic of Scientific Discovery (1959), reprinted (2004) by Routledge, Taylor \& Francis.

[47] M. Saunders, P. Lewis and A. Thornhill, Research methods for business students, 2nd ed., Pearson Education Limited, 2012.

[48] N. Michaelidou and S. Dibb, "Using email questionnaires for research: Good practice in tackling non-response", Journal of Targeting, Measurement and Analysis for Marketing, vol. 14, no. 4, pp. 289-296, 2006. 